\title{
Sobre a bucalidade: notas para a pesquisa e contribuição ao debate
}

\author{
On the concept of buccality: notes for research \\ and contribution to the debate
}

Abstract The article discusses the concept of "buccality" as an expression of social works performed by the human mouth. The reference was the social theory of health (within the field of collective health), focused on social relations and related conflicts. The author situates the theoretical and practical problems faced by collective health as those of its scientificity and the specific way the field participates in social reproduction. He also considers the field's current limits in the collective organization of healthcare as an effect of neo-liberal policies. Problems arising from the concept of collective buccal health were seen as having the same nature and can only be faced using analytical categories from collective health or the social theory of health. The field's scientificity is reiterated by highlighting its proximity with the human sciences, which requires an epistemological repositioning, i.e., its shift from the biomedical terrain and abandonment of the notion of paradigm. Its essential instability is emphasized, characterized in the object and not the method. Final$l y$, the author draws attention to the constitution of "extra-discursive" health structures based on their inclusion among the State's Ideological Apparels, in which the narrative's guiding thread is the critique of ideology.

Key words Public health, Buccality, Epistemology
Resumo Neste artigo é discutido o conceito de bucalidade, entendido como expressão dos trabalhos sociais que a boca humana realiza. Tomouse como referência uma teoria social da saúde, construída no campo da saúde coletiva, que encontra seu foco nas relações sociais e nos conflitos a elas articulado. Foram localizados os problemas teórico-práticos enfrentados pela saúde coletiva, vistos como os da sua cientificidade e do específico modo como participa da reprodução social e considerados seus limites quanto à organização coletiva dos cuidados de saúde, como efeito das políticas neoliberais. Os problemas derivados do conceito da saúde bucal coletiva foram vistos como sendo da mesma natureza, cujo enfrentamento só pode ser realizado com o uso das categorias de análise da saúde coletiva ou teoria social da saúde. Reitera-se a cientificidade deste campo pela explicitação do seu pertencimento às ciências humanas, que exige reposicionamento epistemológico, isto é, seu deslocamento do solo biomédico, e o abandono da noção de paradigma. É afirmada sua instabilidade essencial, caracterizada no objeto e não no método. Finalmente, verifica-se a constituição das estruturas "extradiscursivas" $d a$ saúde, pela sua inclusão entre os Aparelhos Ideológicos de Estado, que tem na crítica da ideologia o fio condutor da narrativa.

Palavras-chave Saúde coletiva, Bucalidade, Epistemologia 
"Nesta peça, nada há de predisposto e preordenado: tudo o que nela acontece e se desenvolve deve ser entendido como tentativa improvisada [...]. Não é em vão que se dá vida a uma personagem." Luigi Pirandello37 (1867-1936)

\section{O problema da saúde bucal coletiva}

Parece que alguns conceitos se tornam ao longo do tempo problemáticos, isto é, a escala de problematizações e de deduções lógicas e inferências que permitem volta-se para eles mesmos e os torna, num certo sentido, e forçadamente, tautológicos. Quer dizer que então, em lugar de permitir a construção de problemas e a correspondente solução, o conceito vem a ser um "problema em si". Ora, se uma ferramenta é "problemática" na sua aplicação ou uso prático, não serve como ferramenta. Se não funciona conforme esperado, engripa-se; se induz deformações no objeto ou se simplesmente é de difícil manuseio, não há que se falar em ferramenta. O mesmo ocorre com conceitos, noções e idéias e, assim vem parecendo com o que denominamos saúde bucal coletiva.

Espera-se haver energia numa categoria dessas porque igualmente se espera que elas sejam traduzidas em políticas e na organização dos processos de trabalho. Por isso, admite-se que as idéias que importam devem se articular ao mundo concreto, ao mundo da ação prática. Isto pode ser facilmente compreendido e demonstrado. Duplo modo de existir, para o sujeito que cogita e para o Outro: é só aqui que os conceitos, as noções, as idéias tomam significado e se efetivam. Isto quer dizer existência (cultural e política) prática. As pessoas querem apenas não pensar bobagens; ninguém quer pensar idéias que não sirvam para nada.

Falando como Thomas Kuhn ${ }^{1}$, pensamos o que deve ser pensado para resolver problemas ou, para ser exato, uns "quebra-cabeças". Thomas Kuhn pensa a partir de uma das formas do pensamento, o científico, e se restringe ao mundo das idéias. Sendo mundo por referência à ciência, nele não há sujeitos. Esta questão será abordada mais adiante, mas o que vale ser ressaltado é que idéias seriam também "forças produtivas", sobretudo se entendemos que os produtos da ideação (teoria) alimentam a vida prática tanto quanto são "forças produtivas" para a produção de novas idéias, isto é, produzem novos pensamentos (Vieira Pinto2).

Um primeiro problema, então, se anuncia: o que dizer da existência prática da saúde bucal coletiva? Como entender ou tornar visível seu "conteúdo tecnológico"? Só nesta dimensão é que a entenderíamos como "ferramenta"? E ela não seria "ferramenta" com condição de possibilidade de produzir "novas ferramentas" ou, ainda, "novos entendimentos" ou "idéias"?

De uma coisa assim constituída poder-seia dizer que funciona como referente, isto é, que contém a possibilidade de ser referência para outras coisas, uma baliza que possa guiar ou escorar qualquer projeto. Por isso falamos em marco teórico e ainda referencial teóricometodológico, pois fica claro que aquele que guia ou referencia contém em germe a chave da explicação e o modo de fazer.

Decorrentemente, um conceito ou categoria, para funcionar como referente ou ser este referencial teórico-metodológico, precisa explicitar o que Althusser ${ }^{3}$ denomina de índice de eficácia, isto é, que tenha como "vantagem teórica" a capacidade de revelar as determinações objetivas e subjetivas que cercam o objeto e permita formular seu "problema teórico".

Ora, como assinala Narvai4, com a saúde bucal coletiva estaríamos longe disso. De fato, em seu artigo o autor encontrou oito possibilidades distintas de significados para esta denominação, excludentes entre si a maior parte delas. Este verdadeiro octólogo seria produzido por efeito das representações dos diferentes grupos (dentistas, entidades, serviços, pesquisadores, reforma sanitária e "bucaleiros"...), cada um a seu modo realizando a reprodução do conceito.

Discutindo a mesma limitação, Moysés \& Sheiham ${ }^{5}$ perguntam se saúde bucal coletiva (SBC) seria um novo paradigma no campo da saúde. Eles entendem, tanto quanto Narvai, haver dispersão de significados ou "mistura" de áreas e disciplinas imbricadas na denominação, e depois, dizendo que "a filiação epistemológica e o consenso discursivo entre os protagonistas ainda não materializam uma identidade científica comum" concluem que dificilmente se encontrarão, entre os autores e personagens que fazem a SBC no Brasil, realizações científicas que apresentem problemas e soluções modelares para uma comunidade de praticantes. Muito menos, ajuntam, teríamos a delimitação consensual dos fatos relevantes a 
serem investigados, com métodos e abordagens adequados e respectivas soluções legítimas.

A inspiração kunhiana é evidente e de fato os autores pensam a saúde bucal coletiva na perspectiva do paradigma. Visto assim, não haveria "identidade científica comum" entre os protagonistas, nem a saúde bucal coletiva se realizaria como ciência, pois estaria longe de ser uma fornecedora de "problemas e soluções modelares para uma comunidade de praticantes".

Moysés \& Sheiham, diante de tão contundente assertiva, e depois pensando que estamos nos "remotos trópicos latino-americanos" e que podem existir "quase-paradigmas", como racionalidades construtivas abertas ao que contestam ou em "diálogo com o real que lhe resiste", se perguntam se não estaríamos "inovando em saúde (bucal) coletiva" e finalizam com a proposição de que a SBC seja "uma racionalidade não dogmática nem normativa, mas aberta ao debate".

Que seja. E, no entanto, há duas distinções notáveis nas abordagens de Narvai e nas de Moysés \& Sheiham a serem consideradas. Enquanto o primeiro vincula o conceito quase imediatamente aos serviços de saúde, e por dentro deles propõe a crítica da odontologia, Moysés \& Sheiham, ao recorrerem à noção de paradigma, dão realce a expressões como "identidade científica", "fatos a serem investigados" e o fornecimento de "problemas e soluções modelares para uma comunidade de praticantes". Mas, os "praticantes" daqui não são os de acolá: paradigma não diz respeito ao "pessoal dos serviços", mas, antes, ao "pessoal da ciência", quer dizer, os cientistas.

Duas considerações devem aqui ser postas, pois o octólogo de Narvai nos remete às formas que a saúde bucal coletiva assume, isto é, aos esquemas de conservação e reprodução segundo os sujeitos envolvidos, enquanto em Moysés \& Sheiham deve-se considerar os elementos constituidores de uma teoria e suas formas elementares, isto é, ao seu componente descritivo.

Em Narvai, trata-se de apreender a saúde bucal coletiva como expressão teórico-política, porque então interessa aos diferentes atores em situação e esses diferentes atores não são outros senão os diferentes sujeitos em ação no campo da saúde coletiva, esta arena que Donnangelo 6 percebeu atravessada pelos conflitos, pela política e pela ideologia. Assim, não é de espantar que sujeitos representem para si uma realidade idealizada, sejam os homens ou a sociedade, seja a saúde ou a odontologia. Mas, ao se retirar o conteúdo crítico do conceito, nele se aniquilam as possibilidades de transformação e criação. Freqüentemente reduzido a um componente "odontológico", vem servindo para justificar a reprodução do mesmo, isto é, interessa aos grupos hegemônicos a conservação das suas práticas, as profiláticas, inclusive, de modo que, nestes casos, assumir a denominação "saúde bucal coletiva" não é mais que um efeito de superfície.

Por outro lado, a produção teórica em SBC é ainda bastante descritiva. Ela dá conta de ser um começo, o ponto inicial, "o princípio decisivo de qualquer desenvolvimento posterior da teoria", porque suas descrições (estudos epidemiológicos, avaliação de produtos e processos, etc.) tornam "possível fazer com que a vasta maioria dos fatos observáveis no domínio que a ela concerne corresponda à definição que ela fornece do seu objeto" (Althusser 3 ).

Moysés \& Sheiham não se equivocam quando pensam produção científica, mas, pelo uso da noção de paradigma, tiveram a mirada reduzida, pois paradigma diz respeito às "ciências duras" e, não só isso, ao modo bastante específico com que Thomas Kuhn encara a história da ciência, em tudo desligada da história dos homens e, assim, anistórica, pois que se passa apenas na cabeça dos cientistas. No entanto, o estudo de Moysés \& Sheiham, marcado por rigor conceitual e metodológico incomuns, é muito pouco "paradigmático", felizmente, e nele ousam a demonstração exitosa de hipóteses pouco testadas.

Seria possível, sem dúvida, pensar da saúde bucal coletiva o seu desarranjo científico, o que a impediria de funcionar como paradigma, isto é, como referente. Ser, portanto, um estruturante. E também não se poderia pensála com a formidável dispersão conceitual que Narvai assinala. Aqui, todavia, se poderia entender esta dispersão como a dos significados, em tudo sempre desbordantes e excessivos em relação ao significante. Na relação entre o significante e o significado há sempre um sujeito; sem ele, o significante jazerá inerte; é por meio dele e nele que significados são produzidos, o produto de um sujeito ativo, ainda que apenas no pensamento.

Pensar o sujeito é pensar no comportamento material do sujeito, e isto nos remete para o terreno das pulsões, do desejo e da política. É a isto que o octólogo de Narvai nos 
conduz, pois, operando cada um daqueles significados, vislumbra-se uma política, modos de organizar a prática, de conceber os serviços, de produzir discursos sobre o paciente, de organizar o ensino, de também fazer ciência. $\mathrm{E}$ não poderia haver paradigma neste lugar, pois os discursos que nele encontramos não são discursos de ciência: no lugar deles encontramos a ideologia do cientista (dos gestores, das entidades, dos dentistas).

Apresentar essas questões é interrogar sobre a organização e o conteúdo do saber científico em cada época, e esta questão precisa ser levantada pois, do contrário, seria manter a ciência num estado puramente descritivo, como se não houvesse relação entre teoria e conhecimento científico com o objeto que faz existir um e outro (Castoriadis 7 ).

De modo que seria conveniente examinar as condições de possibilidade para que se constituam os discursos dos sujeitos, pensando que a ideologia nada tem a ver com a ilusão, com uma representação equivocada e distorcida dos conteúdos sociais, mas, antes, é parte da construção simbólica da realidade (Zizek8). Este autor pensa que a linha separatória entre a verdadeira realidade e a ilusão não é clara, que a realidade nunca é diretamente ela mesma, e que a realidade, tal como a verdade, nunca é, por definição, toda.

A realidade não é o real, isto é, a própria coisa, mas o que vivenciamos como realidade é o real já simbolizado, constituído e estruturado por mecanismos simbólicos - e o problema reside no fato de que a simbolização, segundo Zizek, em última instância, "sempre fracassa, jamais consegue abarcar inteiramente o real, sempre implica uma dívida simbólica não quitada, não redimida". O autor ainda nos lembra que a própria idéia de um acesso à realidade que não seja distorcido por nenhum dispositivo discursivo ou conjunção com o poder é ideológica, não existindo a possibilidade de haver "nível zero" de ideologia nas práticas discursivas. Também não há ideologia que não se afirme distinguindo-se de outra ideologia; o sujeito que realiza este movimento, isto é, o de distinguir entre a "sua" e as "demais" ideologias, requer sempre a construção de um outro corpo de opiniões.

\section{A Saúde Coletiva como campo de práticas e locus de reprodução social}

Diante das explanações precedentes, nas quais se desvelam as "crises" da ciência ou dos paradigmas em saúde, ou o esgotamento do seu referencial teórico-metodológico, torna-se relevante perguntar: haveria uma teoria da saúde coletiva? E teria essa teoria encontrado o ponto da sua suficiência?

Os problemas que cercam a saúde bucal coletiva, no entanto, são extensamente os mesmos que animam a produção teórica da saúde coletiva. São genericamente traduzidos como crises, e a eles vieram se juntar o de certa identidade (Campos', Carvalho10, Goldbaum et al.11, Paim \& Almeida Filho'2).

Sem dúvida, a saúde coletiva vem encontrando ocasião de afirmar uma teoria, e isto aprendemos - arqueologicamente - com Nunes ${ }^{13}$, Minayo ${ }^{14,} 15$, Campos 9 , Ferreira ${ }^{16}$, Paim \& Almeida Filho 12 , e antes com Donnangelo ${ }^{6}$. É bem verdade que estas distintas abordagens implicam momentos diferenciados no percurso da saúde coletiva, mas também é fato que formam o corpus teórico do campo, no qual extensamente as teorias e as práticas parcelares buscam inspiração e referência.

O que se deveria destacar nesta discussão é saber se a "crise do pensamento" que abalaria a saúde coletiva não estaria na dependência da "crise do seu objeto", a um só tempo desvelado como objeto de conhecimento e da organização coletiva do cuidado em saúde. Se assim fosse, se a "crise do objeto" tivesse precedência sobre a "crise do pensamento", então estaríamos diante de um caso de "contaminação" do sujeito pelo objeto, acusação de que não se livram as ciências sociais e humanas.

Seria interessante, por isso, verificar como esta posição se acha implicada nessa Teoria da Saúde Coletiva. Donnangelo 6 assinalou os pontos teóricos fundamentais que cabem nesta discussão. Eles dizem respeito ao objeto, aos modos como se investiga, à proximidade com as ciências sociais e humanas e, por último, seu atravessamento pela ação política. Na abertura do ensaio, a autora afirma que não utilizará definições formais para delimitar o campo, e mais, sem que faça referência ao conjunto de práticas em saúde que a cada momento adquirem especificidade, a abertura de um novo espaço, como ela diz.

Assim, existem as "práticas sanitárias brasileiras", e na relação com estas, a saúde coletiva 
ocupa uma posição. Só por isso, por essa primeira delimitação, a saúde coletiva não se põe como equivalente à "saúde pública", tal como também pensou Minayo15, mas antes oсира um lugar. Tal especificidade se expressa como tendência em se ver ampliada e recomposta em seu espaço de intervenção, quer dizer, o do seu campo de saber e de prática. Se amplia-se e se recompõe, é de produção e reprodução que se trata, que encontrará, todavia, outra forma de especificidade. A produção do conhecimento em Saúde Coletiva incorpora o social, não como variável adicional, mas como um campo estruturado no qual a doença adquire um específico significado. Esta posição mereceu a atenção de Nunes ${ }^{13}$, quando comentou o ensino das ciências sociais na graduação médica, que deslocaria o social para a periferia da formação, e mais, que também na pesquisa a natureza social do homem poderia ser vista como um acréscimo ao biológico, tão somente.

Samaja17, a propósito, nos lembra que os fatos sociais, suas normas e mecanismos de regulação são tão reais quanto os fatos biológicos. Ele insistirá nesta temática para marcar a existência de espaços sociais, que são em tudo diferentes dos biológicos, e diz isso no momento em que a "literatura médico-social parecia apagar estas decisivas diferenças sob o rótulo abstrato de 'o social'”.

Seria, então, este campo estruturado no qual a doença adquire significado, isto é, pela sua internalidade, que a Saúde Coletiva encontraria as condições de sua produção e reprodução. Assim vista, esta Saúde Coletiva é produto histórico. Para Laurell \& Noriega18, também a doença pode ser vista como produto histórico porque a questão do desgaste do corpo vem intimamente articulada à produção e à reprodução dos modos de viver e trabalhar.

Ademais disso, Donnangelo 6 ainda vê as práticas da Saúde Coletiva como parte da história política brasileira, não negando que o campo é imediatamente atravessado por distintas posições diante das possibilidades de organização da vida social.

Ora, organizar a vida social para que se organizem os modos de viver e trabalhar é possibilidade que igualmente se dá como cultura, isto é, de certa forma a produção de redes simbólicas de elaboração e transmissão de experiências e aprendizagem (Samaja17). Ou, como disse Vieira $\mathrm{Pinto}^{2}$, conhecer é condição de existência e, nesta condição, é produto cul- tural. Não seria por esta especificidade, a de participar da organização da vida social, que à Saúde Coletiva se recusaria o estatuto de cientificidade. Parece que desta condição padeceriam todas "as" ciências, escapando dos influxos culturais e históricos - e mais ou menos tão somente as ciências básicas.

Por este motivo, Donnangelo 6 afirmará a transparência e o caráter político da Saúde Coletiva, que não podem ser ocultados por um estatuto de cientificidade, e a um só tempo dirá que as práticas que tomam o "coletivo" como objeto tornam-se tributárias de campos de saber cujo estatuto não se subordina às ciências naturais.

Se não se subordinam às naturais, se subordinarão às sociais e humanas, as mesmas ciências humanas (sociologia, antropologia, direito, economia, psicologia, história, etc.) vistas como co-extensivas e em relação com as disciplinas da saúde, porque partilham todas elas a perspectiva da análise do normal e do patológico, dos conflitos, das regras e dos significados. Além disso, pela agregação dessas disciplinas sociais ao seu próprio campo, exacerbam o desafio de desmedicalizar a saúde (Foucault19, Samaja17).

De fato, não se negam às ciências humanas o seu atravessamento pela vida social genérica, nem elas se livram das polêmicas ou de certas perturbações; e, no entanto, admitem um capital comum de aquisições, conceitos, métodos e procedimentos de verificação. O problema com elas é que freqüentemente revelam coisas ocultas e às vezes reprimidas, e costumamos nos livrar de verdades perturbadoras afirmando que não são científicas e sim políticas. Tal proximidade e atravessamento garantiriam às ciências humanas uma instabilidade essencial, que é como uma permanente tensão entre saberes e poderes (Foucault19, 20, Bour$\operatorname{dieu}^{21}$ ).

Restaria lembrar a questão dos objetos que comparecem neste campo. Donnangelo 6 sustenta que a permanente recomposição das práticas sanitárias propõe novos objetos à pesquisa em saúde coletiva, ressaltando que as práticas de investigação não são uniformes, encontrando no novo espaço aberto, todavia, imediatas condições de desenvolvimento. A autora concluirá que esta produção é marcada por variações temáticas, pela ênfase em distintos objetos e em distintos campos do saber, por variações metodológicas e de análise, por distintas opções sobre modelos experimentais. 
Se os modos de investigar não são os mesmos nos diferentes campos do conhecimento, descrever objetos em Saúde Coletiva é problema e exercício diverso que o colocado para a pesquisa biomédica, médico-cirúrgica ou cirúrgico-odontológica, porque a teoria do problema que terá de ser construída é diferente em um e em outro campo de investigação. Mesmo fortemente gravitada pelas ciências humanas, convém lembrar que a Saúde Coletiva não se esgota nelas, como afirma Ferreira 16 , e que seu atravessamento pelas contradições da vida social a instalam, no limite, como um campo crítico em sua práxis. Decorrentemente, um específico modo de se articular com a (re)produção social, somente possível por meio do seu sujeito.

Paim \& Almeida Filho 12 apresentam como questão preliminar, na análise que fizeram sobre os efeitos do neoliberalismo, a de considerar como os sujeitos que atenderam à convocação para a discussão de tais efeitos vêem o campo social da saúde, e acrescentam a preocupação com o tipo de profissional que atuará nesta nova realidade, quer dizer, a do trabalhador da saúde e sua qualificação e como nele se reproduz (e como ele produz) uma teoria social da saúde.

Faltou acrescentar que neste movimento encontra-se a possibilidade de entender a tão propalada "crise da saúde pública" como ideologia, lembrando Zizek8 para quem é procedimento ideológico reduzir a crise a uma ocorrência externa, em última instância, contingente, deixando assim de levar em conta a lógica inerente do sistema que a gerou.

Isto indicaria que a compreensão de qualquer crise se encontra fora da ciência, que não seria produtora de sujeitos ou, como diz Castoriadis7, a ciência não descobre cientistas, mas coisas. Isto é comentar de outro modo a conhecida expressão de Althusser ${ }^{3}$ para quem todo discurso científico é um discurso sem sujeito, "pois não existe 'sujeito da ciência', a não ser numa ideologia da ciência".

Isto é fácil de compreender, se levarmos em conta que a ciência é produto da razão, enquanto a ideologia interpela os sujeitos nos seus desejos e em suas práticas, necessitadas permanentemente de justificativas e racionalizações. Aqui também reside a diferença entre explicar e compreender, entre objetividade e subjetividade.

Samaja ${ }^{17}$ dedicou todo seu ensaio à abordagem das relações entre produção social e saúde e veremos como este processo se acha imbricado com a ideologia. $\mathrm{O}$ autor pensa um plano primordial da reprodução dos processos sociais e o localiza como o da reprodução das relações de produção, incluindo o regime da propriedade e as formas de distribuição dos meios produtivos. Ora, não sendo a sociedade por inteiro composta pela classe dos proprietários, ao contrário sendo os expropriados desses meios o maior contingente, resulta aberto o conflito entre as classes sociais.

Zizek 8 acerca disto dirá que são numerosas as tentativas de conceber o antagonismo social como coexistência de dois pólos num ambiente neutro, um dogmatismo que colocaria lado a lado a ciência "burguesa" e a ciência "proletária”. Esses pólos, todavia, não encontram jamais a possibilidade da sua convergência, e resulta que a polaridade se verá rompida porque o ambiente que a cerca, não sendo neutro, é o lugar de um terceiro enunciado e jamais o campo neutro compartilhado pelas duas posições antagônicas (sejam sexuais ou de classe). Do mesmo modo, no que concerne à ciência ela não é neutra, quer dizer, seu conhecimento objetivo não se acha por inteiro à disposição de todas as classes sociais. A ciência é una, sem dúvida, mas o que ela expressa é afetado pela luta de classes, a luta por esta ciência única, por quem irá apropriar-se dela ou dos seus produtos.

Da saúde se poderia dizer a mesma coisa, mas o modo como se articula com a reprodução social precisa ser mais bem especificado. Samaja 17 distingue quatro esferas ou dimensões que comportam a reprodução da existência social, como sendo: 1) reprodução biológica; 2) reprodução da autoconsciência; 3 ) reprodução econômica, e 4) reprodução ecológico-política. Não são estanques e, ao contrário, cada um deles contém os outros, funcionam reciprocamente como insumos ou é a sua condição de efetivação. Podia parecer que a saúde comparecesse exclusivamente no processo da reprodução biológica, porque nesta dimensão se localizaria o pólo clínico desta saúde e também todas as suas profilaxias. No entanto, estas práticas se acham profundamente penetradas pela cultura, a segunda dimensão, e depois podemos ver que comparece, junto com outros conhecimentos e práticas, na reprodução da ordem econômica e, finalmente, as várias concepções do processo saúde-doença circulam com familiaridade no mundo da política e das relações estatais. So- 
bre essas múltiplas dimensões, a saúde se abre em suas possibilidades práticas e nelas deposita seus discursos de verdade, as disputas e os conflitos que põem permanentemente neste território os vários sujeitos implicados, a produção e a reprodução de tudo isso, em meio aos impulsos de conservação e transformação dos modos de existir.

A saúde comparece neste campo como parte da (re)produção total da sociedade. Assim, o seu modo de ser não se esgota na forma clínica mas, antes, encontra na interface com outros dispositivos, com os quais partilha as noções de normal e patológico, certo destino natural (Donnangelo6, Samaja17).

\section{De Humana Bucca}

Se afirmamos uma teoria social da saúde, seria conveniente pensar as possibilidades de reorganização da saúde bucal coletiva na mesma perspectiva, pela proposição de novo arranjo teórico-metodológico.

As primeiras referências ao que significa bucalidade podem ser encontradas no prefácio do As palavras e as coisas. Nele, Foucault 19 fez emergir certa cavidade bucal, um palato ou um palácio, em ato de produção e consumo. Primeiro, vem sua natureza amorosa, languidamente considerada Vênus: por ela passam os beijos e as palavras de amor. Mas se agora ela beija e fala, se agora, como dizem Abraham $\&$ Torok 22 , ela se enche de palavras (e de dentes), antes ela estava simplesmente cheia de seio, no gozo inescrupuloso do corpo do outro pois, edêntula, é puramente mammalia. Esta boca sedutora, todavia, não permanecerá o tempo todo em erótica produção. Logo revelará outras habilidades. Foucault encontrará seres de viscosidade e podridão, dirá ele, sob os dentes e a saliva de Eustenes, que antes pusera em ato de mastigação: ele se havia alimentado e já não estava em jejum.

Nesta breve passagem antevemos os trabalhos bucais - a manducação, a linguagem e a erótica - e que são o funcionamento dela, sua fisiologia própria e permanentemente encoberta.

Poder-se-ia dizer que estes três trabalhos se dão como consumo e produção, num movimento que envolve o sujeito em permanente elaboração na fronteira entre razão e desejo. Assim, manducar, isto é, apreender, triturar, insalivar e deglutir, é consumo do mundo, a ação que põe em relação às estruturas visíveis localizadas na parte superior do aparelho digestório com as vísceras não-visíveis localizadas mais abaixo, e tudo isto garante a sobrevivência do homem naquilo que ele tem de natureza, a preservação ou reposição dos elementos que constituem sua unidade corpórea.

Aqui também é produzido o gosto ou a formação do paladar, porque imediatamente, para o homem, o ato de se alimentar é em tudo atividade social, isto é, produzida como cultura. Lembrando Marx ${ }^{23}$, pode-se dizer que a atividade e o gozo também são sociais, tanto em seu modo de existência como em seu conteúdo. Se os sentidos tornam-se capazes de gozo humano, tornam-se sentidos que se confirmam como forças essenciais humanas. Só por isso, a formação dos cinco sentidos é um trabalho e um produto histórico.

Deste modo, para Marx a satisfação e o gozo humanos, o gozo que lhe propiciam os sentidos, não mais se acham prisioneiros de "grosseiras necessidades práticas", pois que estas significam a limitação do sentido. A satisfação e o gozo não podem ser tão somente "necessidades fisiológicas", posto que para o homem que morre de fome não existe a forma humana da comida e seria impossível dizer então em que se distingue esta atividade para se alimentar de uma atividade animal.

É, pois, como cultura, que a satisfação e o gozo bucais esbarram na razão e no desejo: freqüentemente comemos o que não devemos ou o que certa racionalidade recomenda, ou mais ou menos ou, ainda, não do modo como devíamos, de sorte que tudo isto resulta atravessado pelo psiquismo o que põe o sujeito em conflito consigo e com os outros.

Talvez isto ocorra por uma peculiaridade dessas vísceras bucais e do prazer que elas proporcionam. A este propósito, Brillat-Savarin 24 nos lembra que, ao contrário do gozo genital, necessitado sempre de um período de repouso entre uma descarga e outra, os prazeres bucais repetem-se incessantemente. Por isso, sem que haja dispositivos reguladores, a manducação pode tornar-se deletéria para o próprio homem.

O que se diz para a manducação é significativo para os demais trabalhos bucais. Produzimos palavras e as consumimos; somos obrigados a pensar naquilo que falamos, e não raro dizemos o que não queríamos dizer; também a palavra exagerada ou equivocada pode revelarse deletéria. Do mesmo modo, na relação amo- 
rosa produzimos atos bucais sexuais, a retomada da função genital primordial (Aberastury25), o consumo e o deleite com o corpo do outro (agora consentido), e resulta igualmente outra vez o conflito entre razão e emoção (porque não raro esta boca fará o que não devia ou não do modo recomendado, etc.).

Ora, esses três trabalhos são na realidade três dimensões da vida do homem em sociedade, e então seria da produção social da boca humana que deveríamos falar. Simplesmente por este acontecimento ela contém as imensas possibilidades do seu objeto ou, o que dá no mesmo, sua fantástica dispersão, a enorme capacidade que tem de permanentemente ser objeto de representação e de a um só tempo representar a vida do homem para ele mesmo. Só por isso, por este deslizamento, já se encontra essa boca em pertencimento às ciências humanas.

Aqui nos afastamos do terreno da biologia, embora não seja possível ignorar a condição de vizinhança. Lembremos: estamos tratando de vísceras - mucosas, dentes, glândulas, músculos - que em sua delicada solidariedade garantem que a boca não apareça como um órgão ou massa tissular homogênea, mas configure um território.

Na forma das ciências humanas, propicia a emergência de novos objetos. Um objeto não é unívoco em sua materialidade, nem suscita nos sujeitos discursos assemelhados, a partir de pretensa existência objetiva e exterior a impressionar os sentidos. Um objeto é já um constructo, que não aguarda a ordem da sua libertação, encarnado como pura objetividade, mas existirá nas condições positivas de um complexo de relações, entre as quais a que tem com um sujeito. As condições para que surja um objeto de discurso, as condições históricas para que se possa dizer alguma coisa, para que várias pessoas possam dizer coisas diferentes dele, para que se possa inscrevê-lo numa relação de parentesco com outros objetos - as semelhanças, as vizinhanças, o distanciamento, a diferença, a transformação - essas condições são numerosas e o que se estaria a tratar não seria então esse horizonte único de objetividade, mas regras, prescrições, medidas de discriminação e de repressão presentes na prática cotidiana, na jurisprudência, na ordem religiosa, nas descrições patológicas, nos códigos, nas receitas, nos tratamentos e nos cuidados (Foucault20).

Se assim não fosse, de bocas e dentes desde sempre se teria dito mais ou menos as mesmas coisas, e de bocas e dentes as disciplinas apresentariam mais ou menos as mesmas versões. Não é o que observamos, todavia: nas relações, nas situações e nos contextos, bocas e dentes apresentam contornos e significações diferenciados, consoante se trate de discursos odontológicos, psicanalíticos, paleo-antropológicos, ou ainda os da mãe que amamenta ou - enfim - os do próprio sujeito que experimenta na sua cotidianidade as sensações que esses órgãos lhe proporcionam.

É assim que essa bucalidade se desloca do solo odontológico e da carga da disciplina dentária que lhe é próprio, porque a odontologia, historicamente articulada como um constructo biológico, só pode falar dos dentes (e da boca) dos homens como natureza e assim igualmente naturalizar (odontologizar) o adoecimento deles e os procedimentos que adota. Esta é a sua política, ou a representação política do homem que incessantemente elabora, e pela mesma razão nos parecem canhestros seus discursos sociológicos (ou os econômicos, os psicológicos, etc.), assim como as arbitrariedades e artificialismos que emprega para garantir a separação do seu objeto a um só tempo do corpo do homem e da sociedade (Botazzo 26, 27).

Do que tratam, então, esses diferentes discursos? Primeiramente devemos reconhecer que não há lugar, no discurso odontológico, para uma fisiologia bucal, de sorte que imediatamente ficam ressaltados os componentes mecânicos da sua prática, dos quais decorre a ênfase nas técnicas e no adestramento da mão.

Fracassaram as tentativas de compor uma leitura estomatognática da sua clínica e os que ainda insistem nesta abordagem não são mais que resíduos na profissão. Por isto, uma primeira tarefa da saúde (bucal) coletiva seria a de recuperar essa fisiologia e apresentá-la na forma dos trabalhos que a boca realiza.

Difícil ultrapassagem, sem dúvida, porque estamos acostumados com as teorias odontológicas, o que significa centramento dentário. Em si mesmo, este centramento não seria um obstáculo epistemológico. Ocorre, todavia, que, de não haver fisiologia no lugar, a não ser como embriologia, a função dentária, que não é equivalente à função bucal, se vê privada de norma e de normalidade.

Entendamos este ponto. A função, sendo algo que não é visto mas cujo efeito é sentido, em primeiro lugar não expressa relação causal de tipo simples, mas antes opera com base nu- 
ma rede causal, ampla o suficiente para conter ações individuais (a parte) que exibem a mesma propriedade geral no âmbito do coletivo (o todo). Por isso se poderá dizer que a parte é funcional em relação ao todo e, mais, que o conceito de função é inseparável do de organização e de morfogênese. Neste nível as relações de funcionalidade podem ser vistas como causalidade recíproca, em que as causas e os efeitos se configuram como totalidade relacional no qual a ação das partes reproduz o todo. Isto vale quer consideremos o órgão em relação com o organismo ou o do indivíduo com o coletivo de indivíduos (Samaja17).

É deste modo que o conceito de função encontra no conceito de norma o seu par, porque se o organismo responde a estímulos ou a eles se adapta, este organismo age não apenas segundo regularidades, mas segundo condições de existência e a possibilidade de encontrar normas médias de ajustamento que lhe permitem exercer suas funções. Essas normas médias são configurações culturais, e nelas é que emergem os conceitos de normal e patológico e todas as regulações éticas ou sociais que atuam sobre os homens, os quais se encontram mais ou menos liberados dos influxos "biológicos" ou nos quais as regulações biológicas se acham mais ou menos suprimidas ou superadas (Samaja17, Foucault ${ }^{19}$, Canguilhem ${ }^{28}$, Fernandes 29 ).

$\mathrm{Na}$ teoria odontológica falta exatamente este conceito de função. A função dentária nela presente não dá conta de recuperar o homem por inteiro. Tendo por base o órgão dentário isolado, nele encontra espaço suficiente para sustentar sua etiopatogenia restrita e, a partir dela, suas noções sobre o homem em sociedade, seus modos de ser, seus conflitos, sua relação com o próprio corpo (e a própria boca). É neste momento que a odontologia se desvela como biopolítica, com suas regras de limpeza e suas prescrições pastorianas (controle da bucalidade na criança, para ter bons dentes).

Por aqui não há como pensar em função e norma porque simplesmente as peças dentárias podem ser removidas por completo, sem que este drástico evento ameace a existência do indivíduo. Não há norma se não há o órgão, porque falta o objeto por meio do qual será produzido um efeito. Eis a desimportância social e econômica dos órgãos dentários naturais. Substituídos pela dentadura artificial, e assim podendo garantir a produção de algum efeito, esta boca mecanizada torna, obviamente, a manducação um ato mecânico e exterior ao próprio homem. Os discursos odontológicos cessam diante do homem desdentado (e nele se esfuma sua ciência política, suas profilaxias e a porção pública da sua clínica).

A inseparabilidade das vísceras da boca e o conceito de função bucal, os trabalhos que realiza em meio a regulações éticas e sociais, poderiam, ao contrário, representar a possibilidade de a odontologia se reconciliar inicialmente com a clínica (pois função e norma, no caso dos seres vivos, implicam a noção de meio interno e a realidade de sua comunicação sistêmica), e depois reconciliar-se com a sociedade e consigo mesma.

\section{Notas para uma conclusão}

As explanações precedentes permitem deduzir os seguintes pontos, que a pesquisa em saúde bucal coletiva deveria considerar. Eles constituem as superfícies de emergência da bucalidade ou a sua condição de possibilidade:

1) Uma teoria social da saúde (ou a teoria da saúde coletiva) se afirma pela proximidade que mantém com as ciências sociais e humanas, das quais toma por empréstimo seus métodos e referências, por meio dos quais organiza a relação com o campo biomédico. Sua categoria central é a de reprodução social.

2) A boca humana participa (é parte) da reprodução social de específico e singular modo. De fato, nenhuma outra parte da nossa economia animal é tão presente na organização e nos eventos e fatos sociais todos - e de todos os eventos que cercam a vida de um sujeito - que esta. Se os seus trabalhos recobrem tão amplamente a vida do homem em sociedade, a um só tempo a afastam dessa economia e das demais vísceras - suas primas - esse interiora cujo funcionamento acompanhamos: sua autonomia está para o sujeito.

3) A boca humana é lugar institucionalizado e lugar de função institucional, tanto quanto o é a Saúde Coletiva. Quando Campos $^{9}$ comentou os perigos desta institucionalização, antes deveria ter dito aparelhamento: é esta saúde coletiva morta que encontramos em muitos sistemas locais, governos estaduais, departamentos acadêmicos etc. Uma instituição se reproduz e também reproduz os homens bons (palingenesia), que se encarregam disto (Bo- 
tazzo ${ }^{30}$ ). A materialidade do processo saúdedoença indica que a doença e o doente são produtos históricos. Se a boca participa da reprodução social, o faz em meio a prescrições, ritmos, modos, tempos; nisto ela é instituída. E se ela trabalha (produção e consumo), deve se desgastar conforme as solicitações e as possibilidades (ou as condições de existência) do sujeito que está vivo, trabalha e fala. Assim vista, esta bucalidade vem acomodar-se confortavelmente numa Teoria Social da Saúde, esta mesma da qual Cecília Donnangelo fez o insuperável desenho e da qual fez aparecer sua instabilidade essencial como modo de existir (pois essa instabilidade essencial é antes constituída no objeto, isto é, no modo de ser do homem).

4) As variações temáticas, a eleição de objetos, a opção por uma ou outra técnica são expressões de uma prática social dotada de politicidade. Isto se evidencia no discurso odontológico, a um só tempo sincrônico e diacrônico. A odontologia se perfila com o pensamento que lhe é contemporâneo (a episteme de uma época ou a resposta a por que se pensa o que pode ser pensado e do modo como é pensado, e não de outro), mas não se põe limites na recorrência ao passado: busca Pierre Fauchard do início do século 18 para ser o Pai no final do século 19, quando já não havia vantagem teórica nele. Em Fauchard, os dentes são causa de perturbações no corpo do homem e o apodrecimento (caries) bucal é conseqüência das práticas deletérias do sujeito e do mau uso e do mau trato que faz com sua própria boca (Fauchard 31 ). A cariologia contemporânea é expressão acabada desta forma de pensar: a um só tempo desce até as minúcias da biologia molecular, mas não recusa adotar o sujeito como o primeiro inimigo dos próprios dentes. Por isso, numa vertente a cariologia se dá ao modo da ciência; na outra, como ideologia que busca cientificizar-se. Pode-se registrar esse movimento, que é a produção do conhecimento originada nos Departamentos de Odontologia Social: neste lugar o aluno tem confirmado o que é o paciente e sua doença, a "realidade" das políticas públicas e o que pode ou não ser praticado nos serviços de saúde, dando concretude (e justificativa) ao recorte e encolhimento da assistência odontológica no SUS (Narvai ${ }^{32}$ ).
5) A boca humana é corpo humano. Produção e reprodução são eventos que se realizam no corpo do homem, pelo corpo e para o corpo. É aqui que os fenômenos da saúde e da doença se dão como expressão da cultura (incluindo o psiquismo) e se fundem nos nexos poderosos dos modos de produzir a existência. Suporte de ações (e das relações) sociais; são inseparáveis as suas instâncias sensórias e as da razão. Duplo gozo, pois que é o gozo que lhe proporcionam suas mucosas, músculos e glândulas, como Freud mesmo teria dito, e também o gozo da coisa pensada, uma idéia, um raciocínio ou um cálculo. Ele se reveste de cultura e civilização e, nesta, se expressam os controles da sua fisiologia, quer dizer, é no processo civilizador que se instauram dispositivos de controle dos modos de comer, a disposição no leito, o controle dos odores, a depositação das suas excretas, a efetivação da sua limpeza (Elias ${ }^{33}$, Douglas ${ }^{34}$ ). Para si, é um valor de uso, mas não apenas. O corpo é a (única) propriedade do sujeito, o bem que ele dispõe para efetivar-se no mercado de trocas. Sua força de trabalho (energia física e psíquica) é a mercadoria assim disposta. O corpo para si é valor de uso corporificado e disponível socialmente como valor de troca. Talvez se explique o porquê de tantas polêmicas para resolver se a saúde é mercadoria, porque ela é valor de uso, sem dúvida, mas não se entende qual a troca que proporciona (Campos ${ }^{35}$ ). Saúde é estar bem e manter-se com capacidade produtiva, disposta como possibilidade de ação. A doença, ao contrário, limita, tolhe, cerceia ou dificulta a realização desta capacidade. Assim, o corpo adoecido é mercadoria defeituosa, com escasso ou nenhum valor (o sujeito pode se conformar com seu estado, não obrigatoriamente o comprador). O que esperam os usuários dos serviços de saúde? Esperam recuperar essa capacidade, isto é, incrementar valor ao próprio corpo, se capitalizar. É neste duplo entendimento, o de estar ligado ao processo civilizador e ao mercado, que o corpo comparece à clínica, bocas inclusive, nem deveria estranhar que assim seja.

São nessas superfícies e interfaces que uma clínica ampliada, a de acolhimento e desvio (Souza ${ }^{36}$ ), pode se localizar e ter sua possibilidade de efetivação. 


\section{Referências}

1. Kuhn Th S. A estrutura das revoluções científicas. São Paulo: Perspectiva; 1992.

2. Vieira Pinto A. Ciência e existência. Problemas filosóficos da pesquisa científica. Rio de Janeiro: Paz e Terra; 1985.

3. Althusser L. Ideologia e Aparelhos Ideológicos de Estado (notas para uma investigação). In: Zizek S, organizador. Um mapa da ideologia. Rio de Janeiro: Contraponto, 1996. p. 105-42.

4. Narvai PC. Saúde bucal coletiva: um conceito. Odont \& Soc 2001; 3(1-2):47-52.

5. Moysés SJ \& Sheiham A. A saúde bucal coletiva: personagens, autores ou ... Pirandello de novo? In: Kriger L, organizador. Promoção de saúde bucal: paradigma, ciência, humanização. Rio de Janeiro: Artes Médicas; 2003. p. 387-442.

6. Donnangelo MCF. A pesquisa na área da saúde coletiva no Brasil. A década de 70. In: Buss PM, organizador. Associação Brasileira de Pós-Graduação em Saúde Coletiva. Ensino da saúde pública, medicina preventiva e social no Brasil. Rio de Janeiro: Abrasco; 1983. p. 17-35.

7. Castoriadis C. As encruzilhadas do labirinto. Rio de Janeiro: Paz e Terra; 1997.

8. Zizek S. O espectro da ideologia. In: Zizek S, organizador. Um mapa da ideologia. Rio de Janeiro: Contraponto, Rio de Janeiro; 1996. p. 7-38.

9. Campos GWS. Saúde pública e saúde coletiva: campo e núcleo de saberes e práticas. Rev C S Col 2000; 5(2):229-30.

10. Carvalho AI. Da saúde pública às políticas saudáveis. Saúde e cidadania na pós-modernidade. Rev C S Col 1996; 1(1):104-21.

11. Goldbaum M, Botazzo C, Escrivão Jr. A, Manso AX, Mehry EE, Carvalheiro JR et al. Pós-Graduação em Saúde Coletiva. VI Congresso Paulista de Saúde Pública, vol II. São Paulo; 1999. p. 359-60.

12. Paim JS \& Almeida Filho N. A crise da saúde pública e a utopia da saúde coletiva. Salvador: Casa da Qualidade; 2000.

13. Nunes ED. A questão da interdisciplinaridade no estudo da saúde coletiva e o papel das Ciências Sociais. In: Canesqui AM, organizadora. Dilemas e desafios das ciências sociais na saúde coletiva. São Paulo-Rio de Janeiro: Hucitec-Abrasco; 1995. p. 95-113.

14. Minayo MCS. Interdisciplinaridade: uma questão que atravessa o saber, o poder e o mundo vivido. $\mathrm{Me}$ dicina, Ribeirão Preto 1991; 24(2):70-7.

15. Minayo MCS. O desafio do conhecimento. Pesquisa qualitativa em saúde. São Paulo-Rio de Janeiro: Hucitec-Abrasco; 1992
16. Ferreira MAF. Notas sobre a contribuição do cientista social ao campo da saúde. In: Canesqui AM, organizadora. Dilemas e desafios das ciências sociais na saúde coletiva. São Paulo-Rio de Janeiro: Hucitec-Abrasco; 1995. p. 37-51.

17. Samaja J. A reprodução social e a saúde. Salvador: Casa da Qualidade, Salvador; 2000.

18. Laurell AC \& Noriega M. O processo de produção e saúde. Trabalho e desgaste operário. São Paulo: Hucitec; 1989.

19. Foucault M 1990. As palavras e as coisas. Uma arqueologia das ciências humanas. São Paulo: Martins Fontes; 1990.

20. Foucault M. La arqueología del saber. México: Siglo Veintiuno; 1985.

21. Bourdieu P. Questões de sociologia. Rio de Janeiro: Marco Zero; 1983.

22. Abraham N \& Torok M. A casca e o núcleo. São Paulo: Escuta; 1995.

23. Marx K. Manuscritos econômico-filosóficos e outros textos. São Paulo: Abril; 1973.

24. Brillat-Savarin JA. A fisiologia do gosto. Rio de Janeiro: Salamandra; 1989.

25. Aberastury A. El psicoanálisis de niños y sus aplicaciones. México: Paidos; 1986.

26. Botazzo C. A saúde bucal nas práticas coletivas de saúde. São Paulo: Instituto de Saúde; 1994.

27. Botazzo C. Da arte dentária. São Paulo: Hucitec-Fapesp; 2000.

28. Canguilhem G. O normal e o patológico. Rio de Janeiro: Forense-Universitária; 1982.

29. Fernandes F. A sociologia: objeto e principais problemas. In: Ianni O, organizador. Florestan Fernandes. São Paulo: Ática; 1986. p. 48-55.

30. Botazzo C. Saúde pública e saúde coletiva: saberes, interdisciplinaridade e política. Rev C S Col 2000; 5(2):237-40

31. Fauchard P. Le chirurgien-dentiste où traité de dents. Paris: Jean Mariette; 1746

32. Narvai PC. Produção científica na área de odontologia preventiva e social. [tese]. São Paulo: Faculdade de Saúde Pública/USP; 1997.

33. Elias N. O processo civilizador. Uma história dos costumes. Rio de Janeiro: Jorge Zahar; 1992.

34. Douglas M. Pureza e perigo. São Paulo: Perspectiva; 1976.

35. Campos GWS. Um método para análise e co-gestão de coletivos. São Paulo: Hucitec; 2000.

36. Souza ECF. Bocas, câncer e subjetividades. Patografias em análise. [tese]. Campinas: Faculdade de Ciências Médica/Unicamp; 2003.

37. Pirandello L. Seis personagens à procura de um autor. São Paulo: Abril Cultural; 1981. 